Research Article

\title{
Brittleness Risk Evaluation of Mine Safety Based on Brittle Relational Entropy
}

\author{
Chenglang Xiang, ${ }^{1}$ En Zhou, ${ }^{2}$ Rui Hong, ${ }^{1}$ Hui Liu $\left(\mathbb{D},{ }^{1}\right.$ and Xiaomeng Xu ${ }^{1}{ }^{1}$ \\ ${ }^{1}$ College of Quality \& Safety Engineering, China Jiliang University, Hangzhou, China \\ ${ }^{2}$ Zhejiang Fangyuan Test Group Co., Ltd., Hangzhou, China \\ Correspondence should be addressed to Hui Liu; liuhui2003@126.com
}

Received 30 August 2019; Accepted 2 November 2019; Published 14 November 2019

Academic Editor: Mijia Yang

Copyright (c) 2019 Chenglang Xiang et al. This is an open access article distributed under the Creative Commons Attribution License, which permits unrestricted use, distribution, and reproduction in any medium, provided the original work is properly cited.

\begin{abstract}
Mineral extracting involves lots of uncertain factors which take on the typically nonlinear characteristics. To find out the accidents caused by main factors and make clear of disaster-causing factors and risk sources, a modified risk evaluation model-associated interaction effect analysis method was constructed from four aspects of man subsystem, machine subsystem, working environment subsystem, and operations management subsystem. With this model, the theory of brittleness relation was applied to analyze closely the connection between mine safety and various subsystems and their interaction effects on mine safety. Furthermore, brittleness factors were also proposed according to the characteristics of underground mining. Finally, based on data from working fields and investigation results, taking a typical mine as an example, the analysis was carried out. The results show that their entropies of brittle relation were equal to $0.006 \pm 0.201 i,-0.012 \pm 0.221 i, 0.142 \pm 0.237 i$, and $0.041 \pm 0.202 i$, respectively. More exactly speaking, the main brittleness influenced on its safety is the environment subsystem in the mine. Therefore, the key to controlling mine accidents is to introduce advanced equipment and improve mechanization level to reach the intrinsic safety of the mining enterprise. The research proves that the modified risk analysis model based on brittleness relation theory is an effective approach to making clear of the state of mine safety and keeping accidents away in time by taking corresponding measures.
\end{abstract}

\section{Introduction}

According to the statistics of China Statistical Yearbook 2018, the population of China is 1.39 billion, and almost 0.2 billion of the population are insured employees with social security. Statistics have shown that about 38,000 employees had a fatal accident in 2017 and 859 mine employees (375 for coal mining) comprising a certain proportion of the total number of dead employees. Therefore, industrial accidents should be analyzed carefully. Also, risk evaluation should be made. The mining industry accounts for an obvious proportion of work accidents in all industry divisions. Mining, especially coal mining, has been considered as one of the most dangerous occupations in the world and results in severe socioeconomic consequences and life treasures for society and workers [1]. As indicated by the statistical data, the hazards presented in mineral-extracting operations make them unique in the field of industrial safety and health because mineral extracting involves lots of uncertain factors which take on the typically nonlinear characteristics. In China, mineral-extracting industries rank first in occupational diseases, permanent incapacity, fatal accidents, and occupational accidents. Accidents are painfully and costly to workers and their families [2]. Nowadays, the problems in mine safety are prominent, and there are many reasons for these problems. With the development of the times and the advancement of society, the current concern about mine safety has gradually increased. Mine safety has become an important part of the sustainable development of the mining industry, which is attracted widely by all countries' attention. At present, the situation of mine safety production is still severe, which seriously restricts the development of mine enterprises and becomes the bottleneck in China. It is well known that the mine production system is an extremely 
complex system, which is composed of many subsystems, such as human, machine, environment, and so on. The occurrences of accidents have been on obviously uncertain and random characteristics. Once an important element does not work normally, it is likely to bring on the collapse of the production system, which will cause accidents, even enormous disasters. Such characteristics have been called brittleness [3]. The term of brittleness refers to the collapse of one subsystem causing damage to other subsystems because of a coupling relationship between each other, for the reason that brittleness is an inherent property of complex systems and always accompanied by the existence of complex systems [4]. Therefore, how to make the effective analyses and find out the brittle factors of accidents and their relations to control and prevent the accident fundamentally has become one of the major and urgent issues of safety science.

In recent years, the brittleness risk assessment of the disaster-tolerant body is the core issue of disaster risk assessment, and it is also a hot issue discussed by various research organizations of disaster risk assessment in the world. The corresponding evaluation methods can be roughly divided into five categories currently [5], and these methods are proposed based on the index system [6-8], the vulnerability curve $[9,10]$, the layer superposition $[11,12]$, graph theory $[13,14]$, and the cellular automata $[15,16]$, respectively. These methods are widely used in chemical industrial park [5], environmental vulnerability [17], power grids $[18,19]$, flood vulnerability and disaster $[20,21]$, natural gas pipelines [22], firefighting emergency response [23] and groundwater vulnerability [24, 25], and so on. In order to prevent and control disaster accidents, the brittleness of the complex system has been conducted in-depth research at home and abroad. There are some scholars to study the brittleness of the system from different sides. Jin et al. [26] analyzed the brittleness of SARS based on the split test method and explained the process of collapse from the characteristic side of the coal mine accident system; Liu et al. [27] used the theory of brittleness to make clear of the brittle relation between disaster and spontaneous combustion of sulfide ores; Guan and Guo [28] considered the interactive coupling structure constructed by interaction effects among projects as the brittleness risk's internal cause of a project portfolio. Ying et al. [29] proposed a method to analyze and evaluate brittle source of the key procedure in increasing the stability during complex parts' manufacturing. Based on the concept of machining cell, brittleness risk is introduced into the stability analysis of the manufacturing process. The previous studies built the single disaster or accident assessment models from the qualitative, semiquantitative, and quantitative perspectives, while the quantitative study on the brittleness of the coupled multihazard involving lots of uncertainty factors in mine safety is scarce.

Mine production system is a complex system which taking on the typically nonlinear characteristics and involving lots of uncertainty factors. In this paper, brittleness theory has been modified and applied to describe brittleness risk evaluation of mine safety based on brittle relational entropy. This paper is organized as follows: Section 1 introduces the theme and context of the article; Section 2 presents brittleness of the complex system, including essence of brittleness, brittle relation, and their relational entropy; Section 3 describes brittle risk source of the mine safety system in detail and then Section 4 presents an application of the model. Finally, the results obtained and the control strategy provided are discussed in Section 5, and the conclusions of the paper drawn and suggestions for future studies are given in Section 6.

\section{Brittleness Theory of Complex System}

2.1. Essence of Brittleness. Some parts of a system are affected by inside factors of interference which caused the collapse of other parts of the system or the whole complex system as a result of the direct or indirect effect of that behavior. The attribute has been named brittleness of complex system [4]. As a basic attribute of the complex system, brittleness is always accompanied by the complex systems. Therefore, it will not disappear due to the evolution of the system or changes in the external environment. For an open-ended complex giant system, when one of its subsystems has been suffered from a large enough force, the original ordered state will be damaged and then forms a new disordered state. The state has been called the collapse of the subsystem. Because the subsystem exchanges matter and energy with other systems, its collapse will destroy the orderly state of other subsystems that exchange material and energy and eventually collapse. Following these recurrence relations, with the number of collapse systems increasing and hierarchy expanding, the whole complex system would eventually be collapsed [4].

2.2. Brittle Relation. In a complex system, there have been three types of brittle connections between its subsystems or the factors of subsystems due to the interrelated impact of collapse [15], such as the congruity, the discrepancy, and the opposition, according to the theory of set pair analysis (SPA) [30].

SPA, which was firstly proposed by Chinese scholar Zhao in 1989 , is a way of system analysis that portrays and researches on the certainty and uncertainty, as well as their transforming rule existing widely in the system by the concept of set pair and connection degree. Two sets with some relationships were assembled in one pair. Currently, the SPA has been applied to many fields such as social science, engineering technology, management, control system, and research on entropy. Further researches can show the two sets have both common features and opposite sides. According to the theory of SPA, there are $N$ characteristics in total, $S$ is the number of same characteristics, $O$ is the number of opposite characteristics, and $F=N-S-O$ is the number of fluctuant characteristics. Consequently, the congruity, discrepancy, and opposite degree can be expressed in the following equation:

$$
\mu=a+b i+c j
$$

where $a+b+c=1 . A=S / N, b=O / N$, and $c=F / N$ are the measures of the congruity degree, the discrepancy degree, 
and the opposite degree, respectively. $i$ and $j$ are the corresponding coefficients of the discrepancy degree and opposite degree, respectively. The scope of $i$ is $[-1,1]$ and $j=-1$.

2.3. Brittle Relational Entropy. In 1948, Shannon introduced a general uncertainty measure on random variables which taken different probabilities among states into account. According to the theory of Shannon's entropy, the system can be considered as $n$ events, and if probability of every event is $p_{i}(i=1,2, \ldots, n)$, then the degree of uncertainty $H$ $\left(p_{1}, \ldots, p_{n}\right)$ is defined as the following expression:

$$
H\left(p_{1}, \ldots, p_{n}\right)=-k \sum_{i=1}^{n} p_{i} \ln p_{i} .
$$

The subsystems can be described by the changes of states, that is to say, when one of the subsystems is collapsed, the states of the other subsystem that have brittle connection with the one collapsed to some extent. $X$ was supposed as a collapsed input, there exists at least one state $y_{j}(l<j<n)$ of $Y$ that has brittle connection with $X$. Denote the brittle same probability is $p_{\mathrm{a}}\left(y_{j} / X\right)$; denote the brittle fluctuating probability is $p_{\mathrm{b}}\left(y_{j} / X\right)$, and denote the brittle opposite probability is $p_{c}\left(y_{j} / X\right)$, respectively. The three brittle relational probabilities can be expressed as follows:

$$
p_{\mathrm{a}}\left(\frac{y_{j}}{X}\right)+p_{\mathrm{b}}\left(\frac{y_{j}}{X}\right)+p_{\mathrm{c}}\left(\frac{y_{j}}{X}\right)=1 .
$$

And, for their corresponding brittle relational entropy can be expressed as follows:

$$
\begin{aligned}
& H_{\mathrm{a}}=-\sum_{j=1}^{k} p_{\mathrm{a}}\left(\frac{y_{j}}{X}\right) \ln p_{\mathrm{a}}\left(\frac{y_{j}}{X}\right), \\
& H_{\mathrm{b}}=-\sum_{j=1}^{h} p_{\mathrm{b}}\left(\frac{y_{j}}{X}\right) \ln p_{\mathrm{b}}\left(\frac{y_{j}}{X}\right), \\
& H_{\mathrm{c}}=-\sum_{j=1}^{n-k-h} p_{\mathrm{c}}\left(\frac{y_{j}}{X}\right) \ln p_{\mathrm{c}}\left(\frac{y_{j}}{X}\right) .
\end{aligned}
$$

Influences on subsystem $Y$ by $X$ should be the integration of brittle same entropy, brittle fluctuating entropy, and brittle opposite entropy, respectively. Define the brittle relational entropy when $Y$ collapses following the $X$ collapses:

$$
H_{X} Y=w_{\mathrm{a}} H_{\mathrm{a}}+w_{\mathrm{b}} H_{\mathrm{b}}+w_{\mathrm{c}} H_{\mathrm{c}},
$$

where $w_{\mathrm{a}}, w_{\mathrm{b}}$, and $w_{\mathrm{c}}$ are weighty coefficients of brittle same, fluctuating, and opposite entropy, respectively. If the subsystem $Y$ is largest affected by the collapse of $X$, there will be a combination of probability distribution that makes $H_{X} Y$ the maximum.

\section{Brittle Risk Source of Mine Safety System}

3.1. Essence of Brittleness for Mine Safety System. Mineral extracting, involving lots of uncertain factors which taking on the typically nonlinear characteristics, is a comprehensive and technical industry which involves various contents, for example, geology, mining, ventilation, transportation, electromechanical equipment, blasting, and environment protection, as well as organizational management. Compared with other industries, the mining industry is a more labor-intensive industry. It has even worse working conditions and more unsafe factors. In addition, the workplace and the work itself are quite dangerous because the underground working space is narrow, and the explosion of the gas and dust of coal mine, gushing water, underground fire, roof accidents, underground blasting, and so on which take on the direct influence on a mine safety system and threatening the lives, health, and safety of miners. Yan et al. [31] analyzed the safety condition of coal mines by using the theory of man-machine-environment system engineering which was effective to prevent the disasters and accidents. Mine accidents occurred every time, and as a matter of fact, they are related to human unsafe behavior, the state of insecurity of the equipment, destructive environmental conditions, and the organizational operations management. It is precisely because these factors do not work normally and lead to the damage of the mine safety system eventually, and when the degree of damage is more than what the system can accept, the system will collapse.

In this paper, the brittle relation between accidents and mine safety system can be constructed from four aspects of human, machine, environment, and operations management. Assuming that four subsystems can be described with the following state vector set:

$$
S=\left(S_{1}, S_{2}, S_{3}, S_{4}\right),
$$

where $S$ denotes the mine safety system and $S_{1}, S_{2}, S_{3}$, and $S_{4}$ denote human subsystem, machine subsystem, environment subsystem, and operations management subsystem, respectively.

\subsection{Composition of Mine Safety System}

3.2.1. Human Subsystem. The person, who plays an important role in the mine safety system, is the receiver of accident, at the same time, as well as the releaser of the one. Using a miner as an example, it is well known that the miner generally has greater involvement and influence in the process of identifying and characterizing risk; thus, personnel stuff, especially the professional quality building and safety psychology status, has great impact on security. As far as the human subsystem is concerned, the brittle factors can be obtained from the states of physiology and psychology, the professional quality building, and safety training. The state vector set is

$$
S_{1}=\left(s_{101}, s_{102}, \ldots, s_{112}\right),
$$

where $s_{101}$ is the proportion of technical staff; $s_{102}$ is the average age of technicians; $s_{103}$ is the education time of technical staff; $s_{104}$ is the average experience of managers; $s_{105}$ is manager's average length of service; $s_{106}$ is the education time of managers; $s_{107}$ is the education time of works; $s_{108}$ is the average length of service of workers; $s_{109}$ is the proportion of the dispatched workers; $s_{110}$ is the proportion 
of formal workers; $s_{111}$ is the average age of workers; and $s_{112}$ is the average training time for workers.

3.2.2. Machine Subsystem. In the whole mine production system, machine subsystem itself is a complex system which is composed of various types of equipment, especially in a modern mine. Accordingly, there are so many factors impacting safety that it is possible that the system will be collapsed due to these disabled equipment. The state vector set of brittleness factors is

$$
S_{2}=\left(s_{201}, s_{202}, \ldots, s_{215}\right),
$$

where $s_{201}$ is the intact rate of the supporting structure; $s_{202}$ is coverage rate of injecting water into coal seam; $s_{203}$ is coverage rate of grouting after excavating; $s_{204}$ is intact rate of the machines and their protection devices; $s_{205}$ is the level of mining mechanization; $s_{206}$ is of devices exhausting gas; $s_{207}$ is intact rate of drainage equipment; $s_{208}$ is the level of transport mechanization; $s_{209}$ is intact rate of communication facilities; $s_{210}$ is intact rate of monitoring and controlling equipment; $s_{211}$ is intact rate of ventilation facilities; $s_{212}$ is intact rate of dustproof facilities; $s_{213}$ is utilization rate of dustproof facilities; $s_{214}$ is electric apparatus and its protection devices; and $s_{215}$ is intact rate of fireproofing and firefighting facilities.

3.2.3. Environment Subsystem. Statistical analysis of accidents in the mine has shown that the poor working environment is one of the important reasons which caused a high frequency of accidents. From working and geological environments, the brittle factors of the environment can be obtained, and its state vector set is

$$
S_{3}=\left(s_{301}, s_{302}, \ldots, s_{313}\right) \text {, }
$$

where $s_{301}$ is the geological structure; $s_{302}$ is occurrence condition of coal seams; $s_{303}$ is stability of roof and floor; $s_{304}$ is gas geological conditions; $s_{305}$ is the hydrogeology condition; $s_{306}$ is tendency of coal spontaneous combustion; $s_{307}$ is explosiveness of coal seam; $s_{308}$ is temperature; $s_{309}$ is roadway qualification rate; $s_{310}$ is air velocity; $s_{311}$ is the minimum pedestrian width of the roadway; $s_{312}$ is the minimum pedestrian height of the roadway; and $s_{313}$ is concentration of coal dust.

3.2.4. Operations Management Subsystem. The normal operation and mutual coordination of the correlative departments have direct connections with safety production in the mine. The brittle factors of operations management can be obtained from management, coordination of operation, and emergency response, and the state vector set is

$$
S_{4}=\left(s_{401}, s_{402}, \ldots, s_{409}\right),
$$

where $s_{401}$ is safety management; $s_{402}$ is quality control; $s_{403}$ is civilized production; $s_{404}$ is the coordination index of an atmosphere of people's enthusiasm; $s_{405}$ is the coordination index of economic status; $s_{406}$ is the coordination index of ethos; $s_{407}$ is the emergency plan; $s_{408}$ is emergency treatment; and $s_{409}$ is response time.

3.3. Interaction of Mine Safety System. The interactions between the various subsystems in the mine production safety system are different, and the relationship is very complicated. Starting from the mode of action, combined with the influence between subsystems, the interaction of each subsystem can be divided into four types [32]:

(1) Layout interaction, that is, because of the adjacent layout of the subsystem, one system is damaged, and the other system has been also destroyed. Such as the degree of mechanization is not high, it has been lead to an increase in the density of manual operations, which will bring management problems.

(2) Functional interaction, which refers to the normal functioning of a subsystem function, depends on the normal functioning of other subsystem functions associated with it. That is, when the subsystem function associated with it fails, the function of the system may not function properly. For example, coal dust and dust concentration will affect the choice of explosion-proof equipment and facilities, and explosive equipment and facilities will further lead to coordination of management and operation.

(3) Alternative interactions, that is, the functionality of one system can be replaced by the functions of other subsystems associated with it, so when the system fails, it causes an excessive demand for its functional replacement subsystem. If the stability of the top and bottom plates is not good enough, the risk of roof-fall is relatively large, so the requirement for the integrity of the supporting equipment is improved.

(4) Resilience interactions, that is, after the destruction, the functional recovery and repair process will affect each other. When multiple subsystems fail, one of the systems affects the repair process of other subsystems. For example, if the ventilation system is damaged, other system recovery will become very difficult.

The type division of interactions is the embodiment of the mutual influence mechanism. According to the aforementioned classification method, the interaction between the four typical systems of human, machine, environment, and operations management was analyzed. The types of interaction between them and their corresponding influences in the case of severe functional failure are shown in Table 1.

3.4. Modified Brittleness Risk Evaluation Model. Risk identification of the system is the primary work of system risk management and the basis of risk measurement and control. Risk identification of the system mainly includes three aspects: (1) determining what risks the system will be encountered, that is, to identify the risk content; (2) identifying the main influencing factors of the risk; and (3) identifying the consequences caused by the risk. The specific analysis process is shown in Figure 1. 
TABLE 1: Interaction characteristics of the mine safety system in serious failure of function.

\begin{tabular}{lcccc}
\hline \multirow{2}{*}{ Active object/subsystem } & \multicolumn{5}{c}{ Affected object/subsystem } \\
& H-S & M-S & E-S & O\&M-S \\
\hline \multirow{2}{*}{ Human (H-S) } & - & $\bigcirc$ & $\bullet$ & $\triangle$ \\
\hline \multirow{2}{*}{ Machine (M-S) } & $\square$ & & $\bullet$ & $\triangle$ \\
\hline \multirow{2}{*}{ Environment (E-S) } & $\bigcirc$ & - & $\triangle$ & $\bigcirc$ \\
\hline \multirow{2}{*}{ Operations management (O\&M-S) } & $\bullet$ & $\bigcirc$ & $\bullet$ & - \\
\hline
\end{tabular}

-layout interaction, $O$-functional interaction, $\square$-alternative interaction, and $\triangle$-resilience interaction.

Brittle relation analysis model of the mine is proposed according to the brittleness relations of the same, fluctuating, and opposite characteristics between brittle factors of human, machine, environment, and operations management and interactions between the various subsystems. The model architecture is shown in Figure 2.

\section{Case Studies and Results}

Gas explosion has always been a typical accident in coal mines. The gas explosion of a coal mine was used as an example. It is appropriate that the production system of the coal mine has been divided into four parts of human, machine, environment, and operations management according to their brittle relational analyses.

4.1. Data Collection and Processing. The data is obtained according to the analyses above and production conditions of a mining enterprise in Shandong Province, China. In this paper, a five-dimensional vector was taken as the state of the safety of brittle factors. For example, using $(1,0,0,0,0),(0,1$, $0,0,0),(0,0,1,0,0),(0,0,0,1,0)$, and $(0,0,0,0,1)$ as "the safe level," "the comparatively safe level," "the mid level," "the comparatively unsafe level," and "the unsafe level," respectively, "the safe level" was denoted as the brittle relation of the opposite characteristic between the factor and accident; "the comparatively safe level" and "the mid level" were denoted as the brittle relation of the fluctuating characteristic; and "the comparatively unsafe level" and "the unsafe level" were denoted as the brittle relation of the same characteristic. The grading standards of corresponding measures of brittleness risk factors have been shown in Table 2. In order to facilitate the calculation and make out this method, the brittle same, fluctuating, and opposite probability was taken as their corresponding measures of brittleness. Table 3 presents the results of calculation.

4.2. Subsystem Interaction. According to the definition of brittle relational entropy, the layout effect $(L)$ between each subsystem can be characterized as brittleness in the mine production system, and the alternative interaction $(A)$ can be characterized as brittleness opposition; while the functional influence $(F)$ and resilience impact $(R)$ can be characterized as brittle fluctuation. The brittle correlation feature between subsystems in the accident state can be represented by a Boolean matrix. "0" in the matrix indicates that there is no influence between them, and " 1 " indicates that there is mutual influence between them. Then, the Boolean matrix of different types of influence modes is as follows:

$$
\begin{aligned}
L & =\left[\begin{array}{lcccc} 
& H & M & E & O \\
H & 0 & 0 & 1 & 1 \\
M & 0 & 0 & 1 & 0 \\
E & 1 & 1 & 0 & 1 \\
O & 1 & 0 & 1 & 0
\end{array}\right], \\
F & =\left[\begin{array}{lcccc}
H & H & M & O \\
M & 1 & 0 & 0 & 1 \\
E & 0 & 0 & 0 & 0 \\
O & 1 & 0 & 0 & 0
\end{array}\right], \\
R & =\left[\begin{array}{llccc}
H & M & E & O \\
H & 0 & 0 & 1 & 1 \\
M & 0 & 0 & 1 & 1 \\
E & 1 & 1 & 0 & 1 \\
O & 1 & 1 & 1 & 0
\end{array}\right], \\
A & =\left[\begin{array}{lllll}
H & 1 & 0 & 0 & 0 \\
H & 0 & 0 & 0 & 0 \\
O & 0 & 0 & 0 & 0
\end{array}\right] .
\end{aligned}
$$

First, the columns of each matrix have been summed to obtain the integrated matrix $(Z)$ after they were coupled.

$$
I=\left[\begin{array}{ccccc} 
& H & M & E & O \\
L & 2 & 1 & 3 & 2 \\
F & 2 & 1 & 0 & 1 \\
R & 2 & 2 & 3 & 3 \\
A & 1 & 1 & 0 & 0
\end{array}\right] .
$$

Then, each column of the integrated matrix has been summed to obtain the influence relationship between the subsystem and other subsystems: the human subsystem is 7 , the environment subsystem is 5 , the machine subsystem is 6 , and the operation management subsystem is 6 .

Finally, the parameters $P_{\mathrm{a}}, P_{\mathrm{b}}$, and $P_{\mathrm{c}}$ corresponding to the brittleness, brittleness opposition, and brittle fluctuations of each subsystem and their corresponding entropy $H_{a}$, $H_{\mathrm{b}}$, and $H_{\mathrm{c}}$ were calculated. The results are shown in Table 3 .

4.3. Determination of Weighty Coefficients. A catastrophe progression method was used to evaluate the weighty 


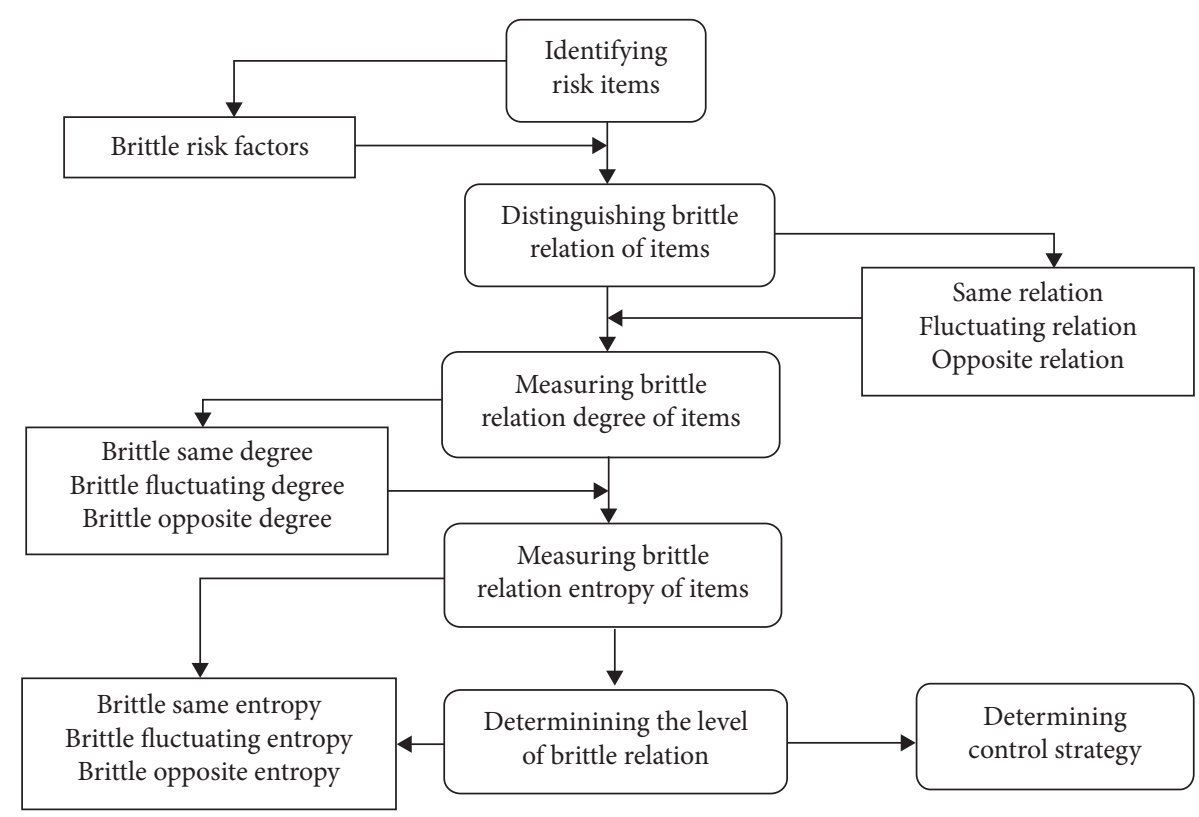

FIGURE 1: Flow diagram of brittleness risk analysis.

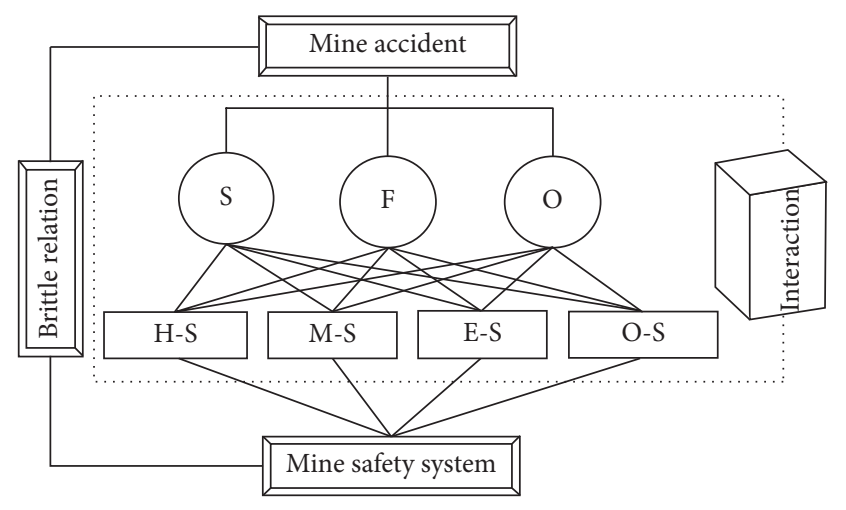

S: same relation

M-S: machine subsystem

F: fluctuating relation

O: opposite relation

H-S: human subsystem

FIgURE 2: Brittle relational analysis model of mine safety, S: same relation, F: fluctuating relation, and O: opposite relation. H-S: human subsystem, M-S: machine subsystem, E-S: environment subsystem, and O-S: operations management subsystem.

coefficients in (13) based on catastrophe theory developed principally by French mathematician Thom for simulating natural phenomena [33]. The potential function has been expressed as follows:

$$
V(x)=\frac{1}{5} x^{5}+\frac{1}{3} a x^{3}+\frac{1}{2} b x^{2}+c x,
$$

where $a, b$, and $c$ are the control variables and $x$ is the state variable. Denote $V^{\prime}(x)=0$ and $V^{\prime \prime}(x)=0$, respectively, then the following set of equations can be obtained:

$$
\left\{\begin{array}{l}
x^{4}+a x^{2}+b x+c=0, \\
4 x^{3}+2 a x+b=0 .
\end{array}\right.
$$

The evaluation can be performed by the three control variables and one state variable. The decomposable form of the bifurcation set can be obtained in the following equation:

$$
\begin{aligned}
& a=-6 \times 2, \\
& b=-8 \times 3, \\
& c=-3 \times 4 .
\end{aligned}
$$

According to equations (14) and (15), the following results can be obtained:

$$
\begin{aligned}
& x_{a}=a^{1 / 2}, \\
& x_{b}=b^{1 / 3}, \\
& x_{c}=c^{1 / 4},
\end{aligned}
$$

where the values of $x, a, b$, and $c$ are between 0 and 1 . The three control variables are, respectively, corresponding to the brittle same, fluctuating, and opposite entropy. Let $w_{a}, w_{b}, w_{c}$ be $x_{a}, x_{b}, x_{c}$, respectively, then

$$
\left\{\begin{array}{l}
w_{a}=H_{a}^{1 / 2}, \\
w_{b}=H_{b}^{1 / 2} \\
w_{c}=H_{c}^{1 / 2} .
\end{array}\right.
$$

The corresponding brittleness entropies can be derived according to equations (5) and (17). The normalized results have been listed in Table 4 .

\section{Result Analysis and Brittle Risk Control Strategy}

From Table 4, it can be found that when $i=1$, the maximum value of brittle relational entropy between mine safety and its four subsystems is $\max \left(S_{1}\right)=0.207, \max \left(S_{2}\right)=0.209$, $\max$ 
TABLE 2: Grading standards of corresponding measures of brittleness risk factors.

\begin{tabular}{|c|c|c|c|}
\hline Subsystem & Factors & Grading standards & Remarks \\
\hline \multirow{12}{*}{ Human } & $s_{101}$ & $<1.5,1.5 \sim 2,2 \sim 2.5,2.5 \sim 3,>3$ & Percentage \\
\hline & $s_{102}$ & $<6,6 \sim 8,8 \sim 10,10 \sim 12,>12$ & Number of years (a) \\
\hline & $s_{103}$ & $<12,12 \sim 13,13 \sim 14,14 \sim 15,>15$ & Number of years (a) \\
\hline & $s_{104}$ & $<8,8 \sim 10,10 \sim 12,12 \sim 15,>15$ & Number of years (a) \\
\hline & $s_{105}$ & $<12,12 \sim 15,15 \sim 18,18 \sim 20,>20$ & Number of years (a) \\
\hline & $s_{106}$ & $<10,10 \sim 11,11 \sim 12,12 \sim 13,>13$ & Number of years (a) \\
\hline & $s_{107}$ & $<8.5,8.5 \sim 10,10 \sim 11.5,11.5 \sim 12.5,>12.5$ & Number of years (a) \\
\hline & $s_{108}$ & $<8,8 \sim 10,10 \sim 12,12 \sim 15,>15$ & Number of years (a) \\
\hline & $s_{109}$ & $<20,20 \sim 30,30 \sim 40,40 \sim 50,>50$ & Percentage \\
\hline & $s_{110}$ & $<50,50 \sim 60,60 \sim 70,70 \sim 80,>80$ & Percentage \\
\hline & $s_{111}$ & $<28,28 \sim 35,35 \sim 42,42 \sim 50,>50$ & Average age \\
\hline & $s_{112}$ & $<3,3 \sim 5,5 \sim 7,7 \sim 9,>9$ & Number of years (a) \\
\hline \multirow{15}{*}{ Machine } & $s_{201}$ & $<65,65 \sim 75,75 \sim 85,85 \sim 95,>95$ & Percentage \\
\hline & $s_{202}$ & $<50,50 \sim 60,60 \sim 70,70 \sim 80,>80$ & Percentage \\
\hline & $s_{203}$ & $<50,50 \sim 60,60 \sim 70,70 \sim 80,>80$ & Percentage \\
\hline & $s_{204}$ & $<65,65 \sim 75,75 \sim 85,85 \sim 95,>95$ & Percentage \\
\hline & $s_{205}$ & $<65,65 \sim 75,75 \sim 85,85 \sim 95,>95$ & Percentage \\
\hline & $s_{206}$ & $<80,80 \sim 85,85 \sim 90,90 \sim 95,>95$ & Percentage \\
\hline & $s_{207}$ & $<80,80 \sim 85,85 \sim 90,90 \sim 95,>95$ & Percentage \\
\hline & $s_{208}$ & $<80,80 \sim 85,85 \sim 90,90 \sim 95,>95$ & Percentage \\
\hline & $s_{209}$ & $<80,80 \sim 85,85 \sim 90,90 \sim 95,>95$ & Percentage \\
\hline & $s_{210}$ & $<80,80 \sim 85,85 \sim 90,90 \sim 95,>95$ & Percentage \\
\hline & $s_{211}$ & $<65,65 \sim 75,75 \sim 85,85 \sim 95,>95$ & Percentage \\
\hline & $s_{212}$ & $70 \sim 75,75 \sim 80,80 \sim 85,85 \sim 90,>90$ & Percentage \\
\hline & $s_{213}$ & $<80,80 \sim 85,85 \sim 90,90 \sim 95,>95$ & Percentage \\
\hline & $s_{214}$ & $<80,80 \sim 85,85 \sim 90,90 \sim 95,>95$ & Percentage \\
\hline & $s_{215}$ & $<80,80 \sim 85,85 \sim 90,90 \sim 95,>95$ & Percentage \\
\hline \multirow{13}{*}{ Environment } & $s_{301}$ & $>1.5,1.5 \sim 1.3,1.3 \sim 1,1 \sim 0.8,<0.8$ & Mean fault drop (m) \\
\hline & $s_{302}$ & $>0.5,0.5 \sim 0.4,0.4 \sim 0.3,0.3 \sim 0.2,0.1 \sim 0.2$ & Variation coefficient of coal seam thickness \\
\hline & $s_{303}$ & $>25,25 \sim 20,20 \sim 15,15 \sim 10,<10$ & Roof management \\
\hline & $s_{304}$ & $>10,10 \sim 8,8 \sim 6,6 \sim 4,<4$ & Gas emission quantity $\left(\mathrm{m}^{3} / t\right)$ \\
\hline & $s_{305}$ & $>10,10 \sim 8,8 \sim 6,6 \sim 4,<4$ & Water-rich coefficient \\
\hline & $s_{306}$ & $<3,3 \sim 5,5 \sim 7,7 \sim 9,>9$ & Self-ignition period (month) \\
\hline & $s_{307}$ & $>20,20 \sim 18,18 \sim 15,15 \sim 12,<12$ & Coal dust explosion index \\
\hline & $s_{308}$ & $>28,28 \sim 26,26 \sim 24,24 \sim 22,22 \sim 18$ & Temperature $\left({ }^{\circ} \mathrm{C}\right)$ \\
\hline & $s_{309}$ & $<80,80 \sim 85,85 \sim 90,90 \sim 95,>95$ & Percentage \\
\hline & $s_{310}$ & $<1,1 \sim 1.5,1.5 \sim 2,2 \sim 2.5,2.5 \sim 3.5$ & Wind speed $(\mathrm{m} / \mathrm{s})$ \\
\hline & $s_{311}$ & $<80,80 \sim 85,85 \sim 90,90 \sim 95,>95$ & Percentage \\
\hline & $s_{312}$ & $<3,3 \sim 5,5 \sim 7,7 \sim 9,>9$ & Number of years (a) \\
\hline & $s_{313}$ & $>10,10 \sim 8,8 \sim 6,6 \sim 4,<4$ & Dust concentration $\left(\mathrm{mg} / \mathrm{m}^{3}\right)$ \\
\hline \multirow{9}{*}{ Operations management } & $s_{401}$ & $<65,65 \sim 75,75 \sim 85,85 \sim 95,>95$ & Percentage \\
\hline & $s_{402}$ & $<65,65 \sim 75,75 \sim 85,85 \sim 95,>95$ & Percentage \\
\hline & $s_{403}$ & $<65,65 \sim 75,75 \sim 85,85 \sim 95,>95$ & Percentage \\
\hline & $s_{404}$ & $<65,65 \sim 75,75 \sim 85,85 \sim 95,>95$ & Percentage \\
\hline & $s_{405}$ & $<65,65 \sim 75,75 \sim 85,85 \sim 95,>95$ & Percentage \\
\hline & $s_{406}$ & $<65,65 \sim 75,75 \sim 85,85 \sim 95,>95$ & Percentage \\
\hline & $s_{407}$ & $<65,65 \sim 75,75 \sim 85,85 \sim 95,>95$ & Percentage \\
\hline & $s_{408}$ & $<65,65 \sim 75,75 \sim 85,85 \sim 95,>95$ & Percentage \\
\hline & $s_{409}$ & $<65,65 \sim 75,75 \sim 85,85 \sim 95,>95$ & Percentage \\
\hline
\end{tabular}

TABLE 3: Corresponding measures of brittleness.

\begin{tabular}{lcccccccc}
\hline \multirow{2}{*}{ Measure } & \multicolumn{2}{c}{ H-S } & \multicolumn{2}{c}{ M-S } & \multicolumn{2}{c}{ E-S } & \multicolumn{2}{c}{ O\&M-S } \\
& $B$ & $I$ & $B$ & $I$ & $B$ & $I$ & $B$ & $I$ \\
\hline Brittle same & $4 / 12$ & $2 / 7$ & $5 / 15$ & $1 / 5$ & $5 / 13$ & $3 / 6$ & $2 / 9$ & $2 / 6$ \\
Brittle fluctuating & $6 / 12$ & $4 / 7$ & $8 / 15$ & $3 / 5$ & $7 / 13$ & $3 / 6$ & $5 / 9$ & $4 / 6$ \\
Brittle opposite & $2 / 12$ & $1 / 7$ & $2 / 15$ & $1 / 5$ & $1 / 13$ & 0 & $2 / 9$ & 0 \\
\hline
\end{tabular}

$B$ : brittle probability; $I$ : interaction probability.
$\left(S_{3}\right)=0.379$, and $\max \left(S_{4}\right)=0.243$, respectively, so $\max \left(S_{3}\right)>$ $\max \left(S_{4}\right)>\max \left(S_{2}\right)>\max \left(S_{1}\right)$. The data show that brittle relational entropy of the environment subsystem is the biggest one and reflects the nature of mining exploitation that is a complex production process. It is not only because there are lots of operation links in mine production but also because the workplaces are changed frequently. The layout of working face, in particular, is subject to the restriction of 
TABLE 4: Corresponding brittleness entropies and weighty coefficients.

\begin{tabular}{|c|c|c|c|c|c|}
\hline \multicolumn{2}{|c|}{ Brittleness entropy } & \multirow{2}{*}{$\begin{array}{c}\text { Same } \\
0.363 \\
0.363^{1 / 2}\end{array}$} & \multirow{2}{*}{$\begin{array}{c}\text { Fluctuating } \\
0.334 \\
0.334^{1 / 3}\end{array}$} & \multirow{2}{*}{$\begin{array}{c}\text { Opposite } \\
0.289 \\
0.289^{1 / 4}\end{array}$} & \multirow{2}{*}{$\begin{array}{c}\text { Relational entropy }^{\mathrm{a}} \\
0.006 \pm 0.201 i\end{array}$} \\
\hline $\mathrm{H}-\mathrm{S}$ & $\begin{array}{c}\text { Values } \\
w_{c}\end{array}$ & & & & \\
\hline M-S & $\begin{array}{c}\text { Values } \\
w_{\mathrm{c}} \\
\end{array}$ & $\begin{array}{c}0.353 \\
0.353^{1 / 2}\end{array}$ & $\begin{array}{c}0.322 \\
0.322^{1 / 3}\end{array}$ & $\begin{array}{c}0.299 \\
0.299^{1 / 4}\end{array}$ & $-0.012 \pm 0.221 i$ \\
\hline E-S & $\begin{array}{c}\text { Values } \\
w_{\mathrm{c}}\end{array}$ & $\begin{array}{c}0.361 \\
0.361^{1 / 2}\end{array}$ & $\begin{array}{c}0.340 \\
0.340^{1 / 3}\end{array}$ & $\begin{array}{c}0.126 \\
0.126^{1 / 4}\end{array}$ & $0.142 \pm 0.237 i$ \\
\hline O\&M-S & $\begin{array}{c}\text { Values } \\
w_{\mathrm{c}}\end{array}$ & $\begin{array}{c}0.356 \\
0.356^{1 / 2}\end{array}$ & $\begin{array}{c}0.301 \\
0.301^{1 / 3}\end{array}$ & $\begin{array}{c}0.244 \\
0.244^{1 / 4}\end{array}$ & $-0.041 \pm 0.202 i$ \\
\hline
\end{tabular}

${ }^{a}{ }_{j}=-1, i \in[0,1] ; w_{c}$ : weighty coefficients.

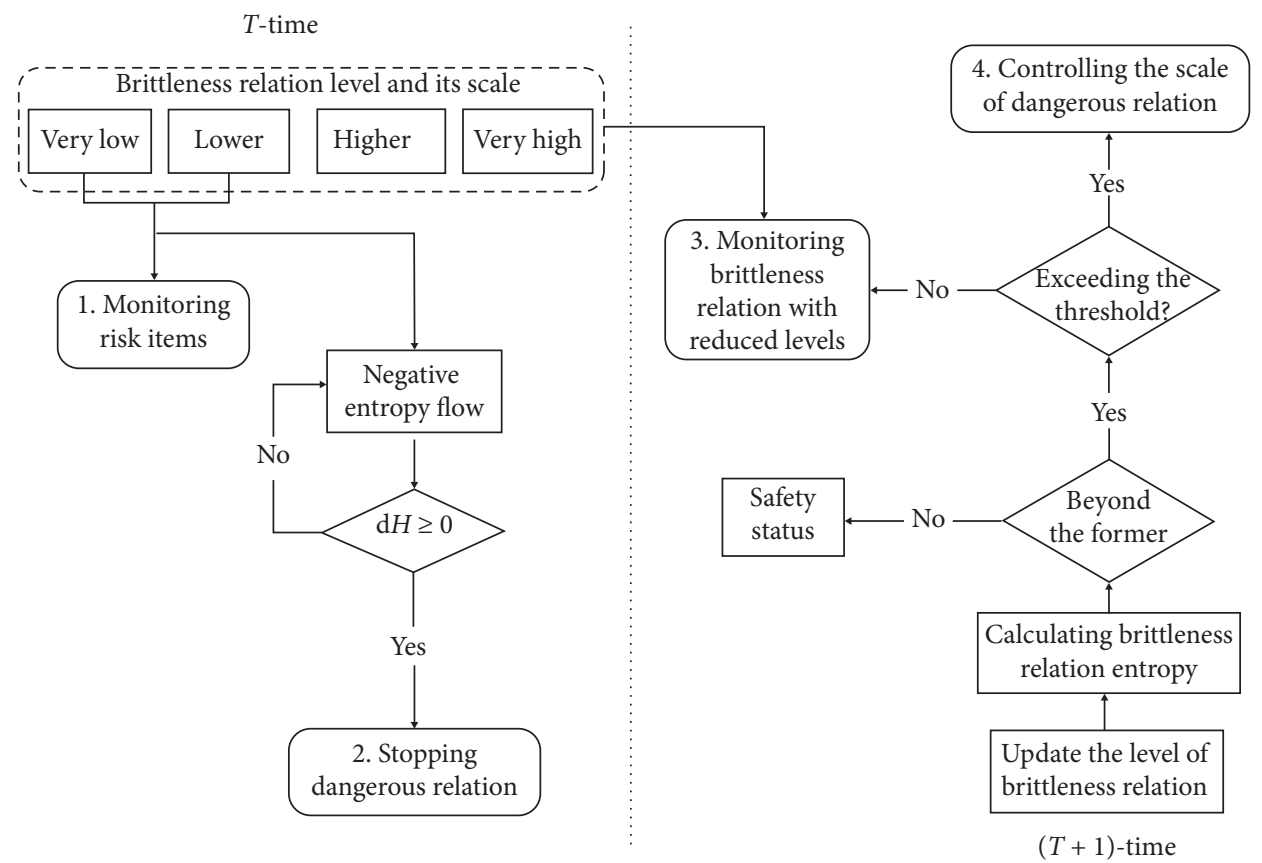

Figure 3: Flow diagram of brittle risk control strategy of the subsystem.

some conditions, such as geological structure, stability of roof and floor, and occurrence condition of coal seams, as well as hydrogeology condition.

Guan and Guo [28] presented some measures to control the brittleness risk for project portfolio based on the brittleness assessment results and the brittle entropy theory. This thinking mode of control strategy is introduced in our work. If the brittleness relation entropy, shown in Table 4, is obtained from the state vector of this subsystem interaction at time $T$, it can be seen from Figure 3 that four risk control points for brittle relation control strategy can be set from two aspects of the horizontal and vertical twodimensional perspectives, and the specific measures are as follows:

(1) Controlling strategy from the vertical to the bottom strategy: for each pair of brittleness relation to determine the corresponding risk system (factor) and set the first risk control point, that is, the dangerous system (factor) has been monitored to prevent the occurrence of brittle collapse events. Furthermore, the negative entropy flows for subsystems consisting of brittleness relation was introduced to prevent accidents by taking measures, such as safety inputs, efficient management, and so on, and the whole process was monitored. If the changes of the brittleness relation entropy $\mathrm{d} H<0$, the state of taking measures will be continuously maintained; otherwise, the second risk control point was set to terminate the brittleness relation which changes the fragile connection structure of the system to prevent or interrupt the occurrence of brittle collapse events.

(2) Controlling strategy from horizontal to edge strategy: since the state vector of the system is not constant, at $T+1$, the brittleness relation level between systems would be made a change. The brittleness relation entropy of the system interaction needs to be recalculated at this time. If the entropy value decreases, it is considered that the composition 
and scale of the brittleness relation at this time are safe; if not, whether it exceeds the security threshold of the predefined brittleness relation entropy should be determined by the management. If it is not exceeded, the third risk control point was set. At this time, it is necessary to monitor the state with the brittleness relation level lower than the previous one. Once the entropy value has exceeded the threshold at this time, it is necessary to control the scale of the risk relation, that is, the fourth risk control point should be set.

According to the theory of brittleness entropy and brittle risk control strategy, the brittleness entropy of accidents reflects the degree of uncertainty of causing accidents, and the bigger the value of entropy is, the greater the risk of causing an accident does. Thus, in order to avoid brittleness of the mine safety system or minimize the brittle influenced by the collapse of some factors, the fundamental method is to obtain negative entropy. The brittle fluctuating entropies of four subsystems are shown in Table 4 ; it can be found that $\Delta\left(B_{3}\right)>\Delta\left(B_{2}\right)>\Delta\left(B_{4}\right)$ $>\Delta\left(B_{1}\right)$, and the brittle fluctuating entropies of environment, machine, and operation management subsystems are the top three, especially the environment subsystem, which have the most notable brittle influence on the mine production system safety. Therefore, the key to controlling mine accidents is to improve the overall working conditions of workers and attach importance to safety management and emergency work. Furthermore, advanced equipment should be introduced to promote mechanization level which will reach intrinsic safety of the mining enterprise.

\section{Conclusions}

The mine production system is extremely complex, whose process of production has much indefinite information. The occurrence of mine accidents is the result of the interaction of various subsystems. The modified brittle relational analysis can effectively be used to determine the relationship of different subsystems with accidents. It proves that it has been one of the most effective means to analyze and find out the most notable brittle relation between accidents and all types of factors. The results of the modified brittle relational analysis indicated that in a coal mine, the main brittle influence on its safety system was the working environment and geological condition. Meanwhile, by combining with the brittle fluctuating entropies of all subsystems, the result shows the environment, machine, and operations management subsystems can provide more room to control mine accidents for further realizing the intrinsic safety of mine production. It is beneficial for the decision-makers and supervisors to make clear of the state of the mine and to keep accident away in time by attaching importance to safety management, introducing advanced equipment, and updating old equipment in time to improve mechanization level.

\section{Data Availability}

The data used to support the findings of this study are available from the corresponding author upon request.

\section{Conflicts of Interest}

The authors declare that they have no conflicts of interest.

\section{Acknowledgments}

This work was supported in part by the National Natural Science Foundation of China (nos. 51104134 and 51804287), the Zhejiang Provincial Natural Science Foundation of China (no. LY14E040001), the Science and Technology Project of Department of Education of Zhejiang Province (no. Y201942504), and the Key Laboratory of Safety Engineering and Technology Research of Zhejiang Province (no. 201904).

\section{References}

[1] M. Ishtiaq, N. Jehan, and Z. Rehman, "Factors associated with occupational injuries in coal miners," Journal of Medical Sciences, vol. 22, no. 1, pp. 21-24, 2014.

[2] S. Ural and S. Demirkol, "Evaluation of occupational safety and health in surface mines," Safety Science, vol. 46, no. 6, pp. 1016-1024, 2008.

[3] Q. Wei, H. Jin, and J. Guo, "Research on complex system based on brittleness," System Engineering, vol. 19, no. 3, pp. 326-328, 2004.

[4] Q. Wei, H. Jin, X. Yao, and J. Guo, "Collapse of complex system based on brittleness," Journal of Harbin Engineering University, vol. 24, no. 2, pp. 161-165, 2003.

[5] G. Chen, K. Huang, M. Zou, Y. Yang, and H. Dong, "A methodology for quantitative vulnerability assessment of coupled multi-hazard in chemical industrial park," Journal of Loss Prevention in the Process Industries, vol. 58, pp. 30-41, 2019.

[6] A. Fekete, "Validation of a social vulnerability index in context to river-floods in Germany," Natural Hazards and Earth System Sciences, vol. 9, no. 2, pp. 393-403, 2009.

[7] M. S. Kappes, M. Papathoma-Köhle, and M. Keiler, "Assessing physical vulnerability for multi-hazards using an indicator-based methodology," Applied Geography, vol. 32, no. 2, pp. 577-590, 2012.

[8] R. Zhao, S. Liu, Y. Liu, L. Zhang, and Y. Li, "A safety vulnerability assessment for chemical enterprises: a hybrid of a data envelopment analysis and fuzzy decision-making," Journal of Loss Prevention in the Process Industries, vol. 56, pp. 95-103, 2018.

[9] E. Wijayanti, S. Kristiawan, E. Purwanto, and S. Sangadji, "Seismic vulnerability of reinforced concrete building based on the development of fragility curve: a case study," Applied Mechanics and Materials, vol. 845, no. 7, pp. 252-258, 2016.

[10] N. Khakzad and P. Van Gelder, "Vulnerability of industrial plants to flood-induced natechs: a Bayesian network approach," Reliability Engineering \& System Safety, vol. 169, pp. 403-411, 2018.

[11] N. Hammouri and A. Elnaqa, "GIS based hydrogeological vulnerability mapping of groundwater resources in Jerash Area-Jordan," Geofisica Internacional, vol. 47, no. 2, pp. 8597, 2008. 
[12] M. Jia, G. Chen, and G. Reniers, "Equipment vulnerability assessment (EVA) and pre-control of domino effects using a five-level hierarchical framework (FLHF)," Journal of Loss Prevention in the Process Industries, vol. 48, no. 7, pp. 260269, 2017.

[13] F. Argenti, G. Landucci, G. Reniers, and V. Cozzani, "Vulnerability assessment of chemical facilities to intentional attacks based on bayesian network," Reliability Engineering \& System Safety, vol. 169, pp. 515-530, 2018.

[14] N. Khakzad, G. Reniers, R. Abbassi, and F. Khan, "Vulnerability analysis of process plants subject to domino effects," Reliability Engineering \& System Safety, vol. 154, pp. 127-136, 2016.

[15] H. Jin, D. Lin, Q. Wei, and J. Guo, "On the brittleness of infectious disease diffusion with theory cellular automation," System Engineering, vol. 22, no. 10, pp. 5-8, 2004.

[16] A. V. Gheorghe, D. V. Vamanu, P. F. Katina, and R. Pulfer, "Use of cellular automata in assessment of risk and vulnerability," Critical Infrastructures, Key Resources, Key Assets, vol. 34, pp. 131-148, 2018.

[17] J. Zhao, G. Ji, Y. Tian, Y. Chen, and Z. Wang, "Environmental vulnerability assessment for mainland China based on entropy method," Ecological Indicators, vol. 91, pp. 410-422, 2018.

[18] R. Fang, R. Shang, Y. Wang, and X. Guo, "Identification of vulnerable lines in power grids with wind power integration based on a weighted entropy analysis method," International Journal of Hydrogen Energy, vol. 42, no. 31, pp. 20269-20276, 2017.

[19] Y. Che, J. Jia, Y. Zhao, D. He, and T. Cao, "Vulnerability assessment of urban power grid based on combination evaluation," Safety Science, vol. 113, pp. 144-153, 2019.

[20] W. Yang, K. Xu, J. Lian, C. Ma, and L. Bin, "Integrated flood vulnerability assessment approach based on TOPSIS and Shannon entropy methods," Ecological Indicators, vol. 89, pp. 269-280, 2018.

[21] Y. Liu, M. You, J. Zhu, F. Wang, and R. Ran, "Integrated risk assessment for agricultural drought and flood disasters based on entropy information diffusion theory in the middle and lower reaches of the Yangtze River," International Journal of Disaster Risk Reduction, vol. 38, pp. 101-194, 2019.

[22] C. P. Medeiros, M. H. Alencar, and A. T. de Almeida, "Multidimensional risk evaluation of natural gas pipelines based on a multicriteria decision model using visualization tools and statistical tests for global sensitivity analysis," $R e$ liability Engineering \& System Safety, vol. 165, pp. 268-276, 2017.

[23] A. W. Righi, G. J. Huber, J. O. Gomes, and P. V. R. de Carvalho, "Resilience in firefighting emergency response: standardization and resilience in complex systems," IFAC-PapersOnLine, vol. 49, no. 32, pp. 119-123, 2016.

[24] K. Khosravi, M. Sartaj, F. T.-C. Tsai et al., "A comparison study of DRASTIC methods with various objective methods for groundwater vulnerability assessment," Science of the Total Environment, vol. 642, pp. 1032-1049, 2018.

[25] J. Wang, S.-c. Li, L.-p. Li, P. Lin, Z.-h. Xu, and C.-1. Gao, "Attribute recognition model for risk assessment of water inrush," Bulletin of Engineering Geology and the Environment, vol. 78, no. 2, pp. 1057-1071, 2019.

[26] H. Jin, H. Wu, D. Lin, P. Xue, and J. Zhao, "Interior brittleness process of coalmine accident system," Journal of System Engineering, vol. 22, no. 5, pp. 449-454, 2007.

[27] H. Liu, C. Wu, Z. Li, and F. Yang, "Brittleness risk source for spontaneous combustion of sulfide ores," Journal of Central
South University (Science and Technology), vol. 42, no. 3, pp. 752-757, 2011.

[28] D. Guan and P. Guo, "Brittleness risk Analysis of project portfolio based on brittle link entropy," Chinese Journal of Management, vol. 12, no. 10, pp. 1553-1561, 2015.

[29] X. Ying, M. Rong, and Q. Hu, "An evaluation method for brittle source of the key procedure in complex parts manufacturing," Mathematical Problems in Engineering, vol. 2018, Article ID 1952674, 11 pages, 2018.

[30] K. Zhao, "Study entropy based on the set pair analysis," Journal of Zhejiang University, vol. 6, no. 2, pp. 69-73, 1992.

[31] Z. Yan, X. Wang, and Y. Fu, "Study on early warning model of coal mining engineering with fuzzy AHP," Systems Engineering Procedia, vol. 5, pp. 113-118, 2012.

[32] A. Liu, C. Wu, and W. Xu, "Damage sensitivity evaluation of urban lifeline based on brittleness entropy," Journal of Central South University (Science and Technology), vol. 47, no. 8, pp. 2793-2801, 2018.

[33] W. Huang, X. Zhang, C. Li, F. Wang, and Z. Ma, "Coupling analysis of disaster bearing capacity of urban lifeline system based on brittleness entropy," Computational Water, Energy, and Environmental Engineering, vol. 3, no. 3, pp. 119-127, 2014. 


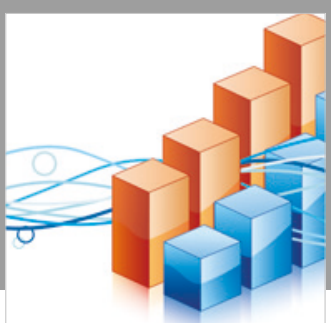

Advances in

Operations Research

\section{-n-m}
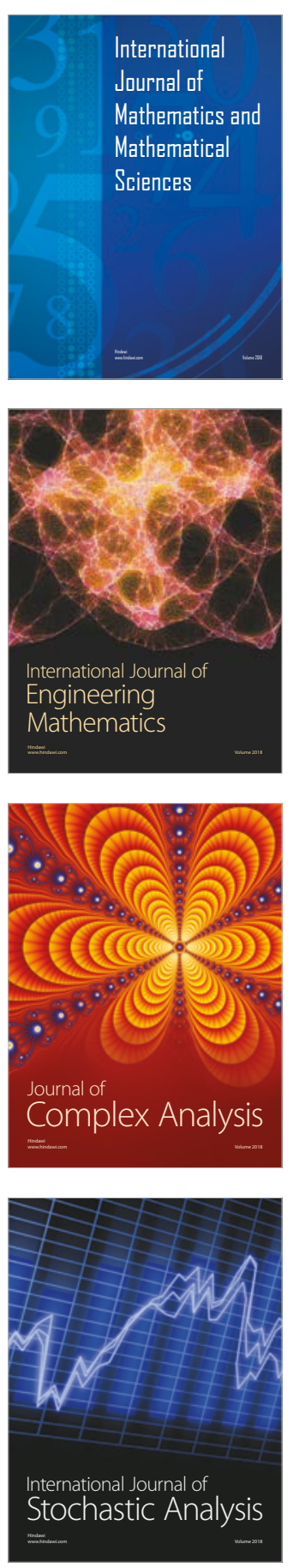
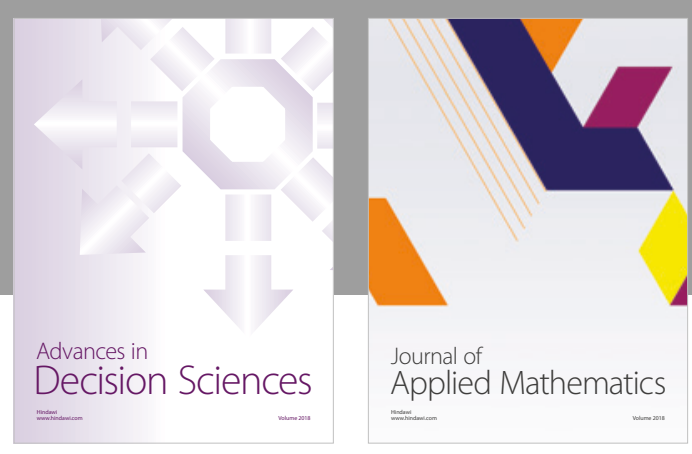

Journal of

Applied Mathematics
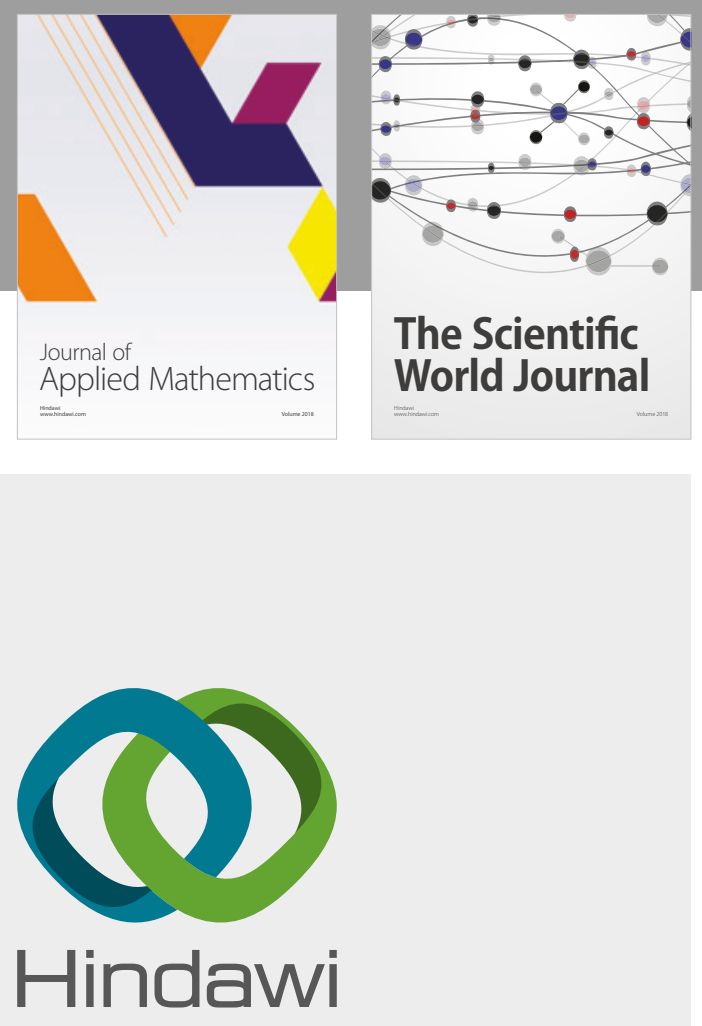

Submit your manuscripts at

www.hindawi.com

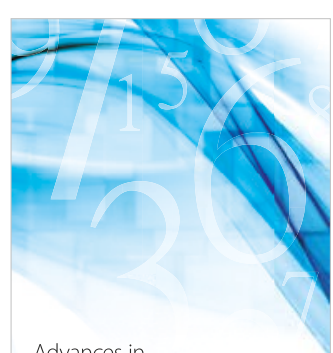

Advances in
Numerical Analysis
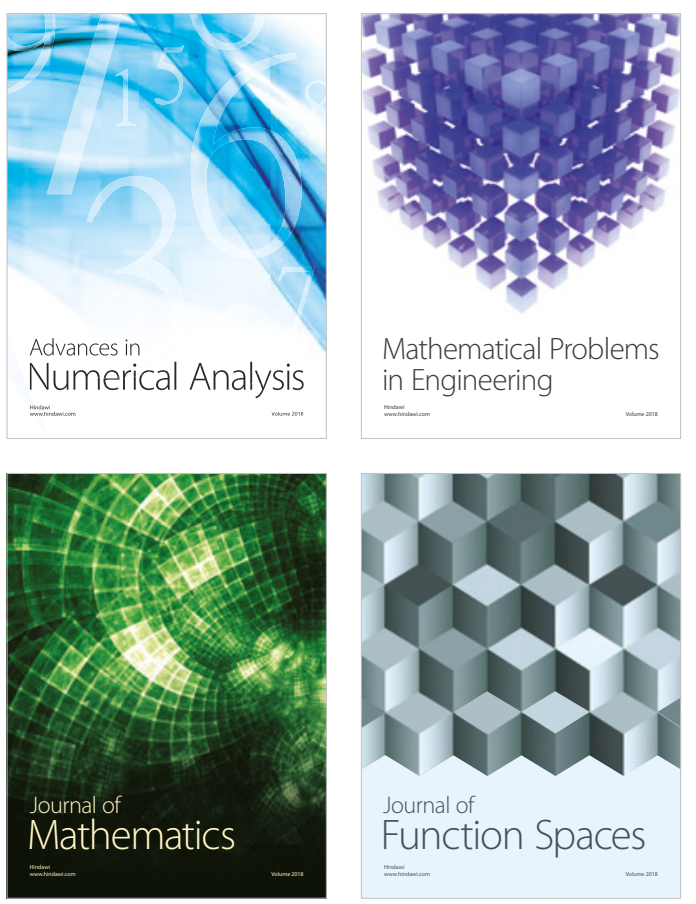

Mathematical Problems in Engineering

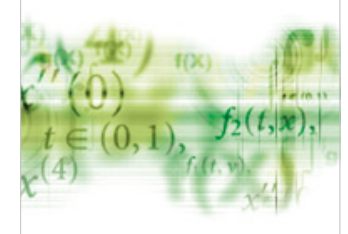

International Journal of

Differential Equations

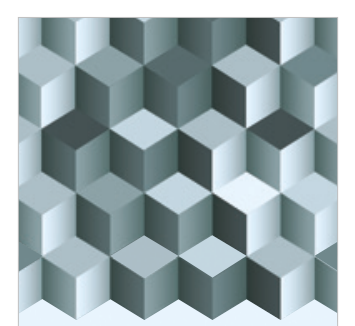

Journal of

Function Spaces

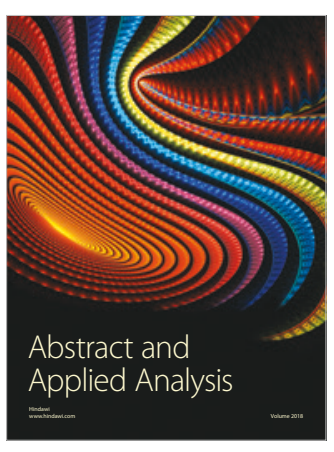

The Scientific

World Journal

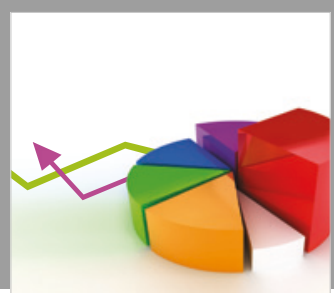

Journal of

Probability and Statistics
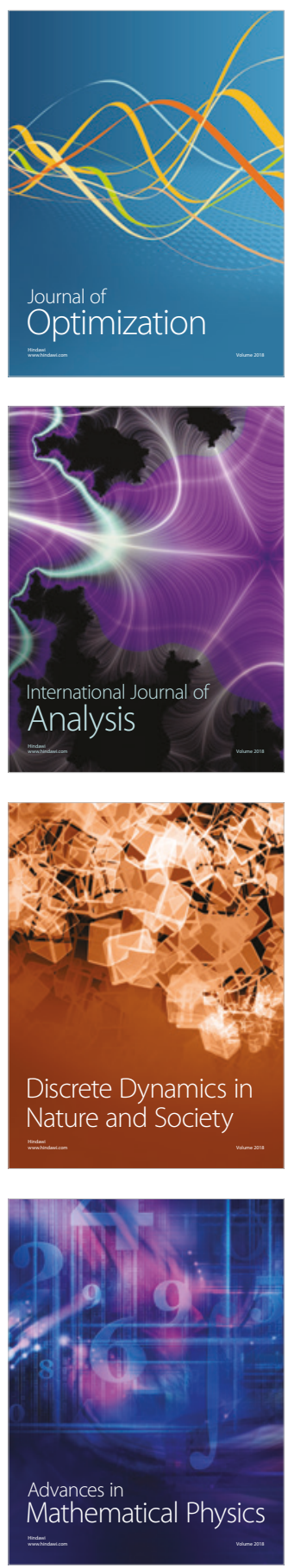